\title{
Variability of the Initial Phase of the Ventilatory Response to Hypoxia in Sleeping Infants
}

\author{
HEIDI L. RICHARDSON, PETER M. PARSLOW, ADRIAN M. WALKER, RICHARD HARDING, AND ROSEMARY S. C. HORNE \\ Ritchie Centre for Baby Health Research [H.L.R., P.M.P., A.M.W., R.S.C.H.], Department of Physiology [R.H.], Monash University, \\ Clayton, Victoria 3168, Australia
}

\begin{abstract}
Most of the available data on the hypoxic ventilatory response (HVR) in infants has been obtained in quiet sleep (QS), and only one study has made repeated tests in the same infant. We aimed to gain a more complete knowledge of the maturation and consistency of the initial phase of the HVR by performing multiple tests in both QS and active sleep (AS) over the first 6 mo of life in term infants. Fifteen healthy term infants were studied with daytime polysomnography longitudinally at 2-5 wk, 2-3 mo, and 5-6 mo after birth. Each infant received multiple hypoxic $\left(15 \% \mathrm{O}_{2}\right.$, balance $\mathrm{N}_{2}$ ) challenges (three or more) in both AS and QS. In AS, infants consistently aroused to hypoxia; however, in QS, infants both aroused and failed to arouse. The initial phase of the HVR varied considerably between infants with the changes in ventilation $/ \mathrm{kg}$ [SD of inspired minute ventilation per kilogram of body weight $\left.\left(\dot{\mathrm{V}}_{\mathrm{I}} / \mathrm{kg}\right)\right]$ being more variable during AS than QS at all three ages and overall decreasing with postnatal age in both sleep states. The variability between replicate $\dot{\mathrm{V}}_{\mathrm{I}} / \mathrm{kg}$ measurements was also significantly greater in AS compared with QS at 2-5 wk postnatal age. There was no evidence of habituation to repeated hypoxic tests in either sleep state. Our study has demonstrated that the initial phase of the HVR is variable both between and within term infants in both AS and QS, with responses being markedly more variable during AS, and becoming more consistent with increasing postnatal age. By performing only one test or by failing to account for arousal responses, previous studies may not have detected the natural variation of the infant HVR. (Pediatr Res 59: 700-704, 2006)
\end{abstract}

$\mathrm{D}^{\mathrm{n}}$ uring sleep, the regulation of respiration undergoes important changes in both adults and infants. Sleep is associated with hypotonia of various respiratory muscles such as the genioglossus, masticatory, and deep neck muscles (1), and this can lead to increased upper airway resistance (2) and reduced functional residual capacity (3). Minute ventilation is also decreased during sleep (by approximately $8 \%-15 \%$ in adolescents and adults) when compared with wakefulness (4). With a loss of the wakefulness drive to breathing and the variability of respiratory control between different sleep states, responses to respiratory stimuli are altered during sleep (5); thus, physiologic challenges such as hypoxia, hypercapnia,

Received September 21, 2005; accepted December 14, 2005.

Correspondence: Rosemary Horne, Ph.D., Ritchie Centre for Baby Health Research, Level 5, Monash Medical Centre, 246 Clayton Road, Clayton, Victoria, Australia 3168; e-mail: rosemary.horne@med.monash.edu.au

This project was supported by the National Health and Medical Research Council of Australia and the Sudden Infant Death Research Foundation of South Australia.

DOI: 10.1203/01.pdr.0000214978.94064.66 and airway obstruction can pose a greater risk when asleep than when awake.

The HVR is a key protective mechanism aimed at maintaining adequate blood oxygen levels. In adults, the response consists of a prompt increase in ventilation, which peaks within 3-5 min of exposure to hypoxia, followed by a period of sustained hyperventilation for 15-30 $\mathrm{min}$ (6). In contrast, studies in infants have reported an increase in ventilation during the first 1-2 min of hypoxic exposure, followed by a reduction to or below normoxic levels within 5 min, suggesting an immature HVR that is biphasic in nature. This biphasic response has been demonstrated in both term (7-9) and preterm infants (10-15).

Previous studies in infants have primarily been conducted in QS; however, as infants spend the majority of their sleep time in AS, it is important to understand the HVR in this state too. Furthermore, in the majority of studies, only a single HVR test in each infant was performed; only one study made repeated measurements in the same infant (7). Thus, the consistency of the HVR in term infants has not yet been established. Studies in adults have shown a significant variability in individual responses to hypoxia in both rapid eye movement (REM) sleep and non-REM (NREM) sleep (16). In addition, studies in adults have demonstrated that the oxygen saturation at which arousal occurs varies between subjects (16). Arousal is a vital protective mechanism in the event of an inadequate HVR; however, despite the importance of arousal, studies in infants have usually not accounted for arousal responses when investigating the infant HVR.

Our present aim was to investigate the maturation and consistency of the initial phase of the HVR by studying healthy term infants longitudinally over the first 6 mo of life; infants have been repeatedly challenged in both sleep states, and arousal responses have been taken into consideration.

\section{METHODS}

Ethical approval for this project was obtained from the Southern Health and Monash University Human Research Ethics Committees. Written in-

Abbreviations: AS, active sleep; HVR, hypoxic ventilatory response; QS, quiet sleep; REM, rapid eye movement; $\mathbf{S p o}{ }_{2}$, oxygen saturation; $\dot{\mathbf{V}}_{\mathbf{I}} / \mathbf{k g}$, inspired minute ventilation per kilogram of body weight 
formed parental consent was obtained before each investigation. Participation in the study was entirely voluntary with no monetary incentive provided.

Subjects. Data were collected from a group of 15 healthy term infants recruited from Jessie McPherson Private Hospital and the maternity wards at Monash Medical Centre, Melbourne, Australia. Infants were born at 38-41 wk of gestation (mean $40 \pm 0.3 \mathrm{wk}$, mean $\pm \mathrm{SEM}$ ) with normal birth weights of $3110-4725 \mathrm{~g}$ (mean $3549 \pm 132 \mathrm{~g}$ ). Apgar scores were median 9 at $1 \mathrm{~min}$ (range 3-9) and median 9 at 5 min (range 6-10). Infants were studied at 2-5 wk (mean $22 \pm 0.8 \mathrm{~d}$, range 17-26 d), 2-3 mo (mean $72 \pm 1 \mathrm{~d}$, range 68-84 d), and 5-6 mo (mean $164 \pm 2$ d, range 157-175 d) after birth. None of the mothers reported smoking during pregnancy or after delivery, and this was confirmed with infant urinary cotinine analysis (17).

Sleep diaries were completed by the parent(s) for $2 \mathrm{~d}$ preceding each study to ensure that sleep observed in the laboratory was comparable with typical sleep patterns in the home.

Polysomnographic recording variables. A 16-channel polygraph (Model 78A, Grass Instrument Co., Quincy, MA) was used to record an electroencephalogram, electro-oculogram, submentalis electromyogram, electrocardiogram, and instantaneous heart rate. Thoracic and abdominal breathing movements were recorded using Resp-ez Piezoelectric sensors (EPM Systems, Midlothian, VA); oxygen saturation $\left(\mathrm{Spo}_{2}\right)$ was recorded from a pulse oximeter attached to the ear (BIOX 3700e, Ohmeda, Louisville, CO); transcutaneous carbon dioxide was recorded using a carbon dioxide electrode (Model E5280, Radiometer, Copenhagen, Denmark). Abdominal skin temperature was also recorded (YSI 400 Series Thermistor, Mallinckrodt, Melbourne, VIC, Australia).

Nasal airflow was measured using a small purpose-built pneumotachograph attached to a specially designed silicone rubber nose mask, as described previously $(17,18)$. Briefly, a continuous flow of medical grade gas was passed across the pneumotachograph at a constant rate of $5 \mathrm{~L} / \mathrm{min}$, producing a pressure of $0.25 \mathrm{~cm} \mathrm{H} \mathrm{H}_{2} \mathrm{O}$ within the mask. Expired carbon dioxide $\left(\mathrm{PETCO}_{2}\right)$ was monitored at a sampling rate of $100 \mathrm{~mL} / \mathrm{min}$. A differential transducer attached to the pneumotachograph was electronically balanced to account for the bias flow and capnograph gas withdrawal.

Study protocol. Polysomnography was performed between 1000 and $1600 \mathrm{~h}$. Environmental temperature was maintained at $21-24^{\circ} \mathrm{C}$ throughout the studies, while noise and light levels were kept to a minimum. Following electrode attachment, infants were placed supine in a bassinet to sleep. Sleep state was determined as AS, QS, or indeterminate sleep according to standard criteria (19); data from indeterminate sleep were excluded from analyses.

At the beginning of each sleep period, after application of the mask, a 2-min control period ensured the infant was settled into stable sleep and provided baseline cardiorespiratory values. A further 1-min control period was obtained before each hypoxic test and provided baseline cardiorespiratory and respiratory gas values. Infants were challenged with hypoxia by using a custom-drilled three-way tap (Swagelock, $\mathrm{OH}$ ) to change the inspired gas supply from air $\left(21 \% \mathrm{O}_{2}\right)$ to $15 \% \mathrm{O}_{2}$ (balance $\mathrm{N}_{2}$ ). Tests were terminated under three conditions: (1) when the infant aroused, (2) after 5 min with no arousal, or (3) if $\mathrm{SpO}_{2}$ fell below 85\%. Replicate tests $(n \geq 3)$ were obtained in each sleep state. Between successive challenges, recovery periods of at least 2 min allowed the infant to reestablish normal respiration.

Tests were not performed during periodic breathing; tests that induced periodic breathing were continued until one of the termination criteria was met, but were not included in analyses. Data from tests which were terminated when $\mathrm{SpO}_{2}$ fell to $\leq 85 \%$ were also excluded from further analyses.

Arousal criteria. Subcortical activation from sleep was determined according to four criteria, with the simultaneous presence of at least three required to designate an arousal response (20-22). This classification of arousal is consistent with the recent definition by the International Paediatric Work Group on Arousals (23). Based on appropriate responses to avoid or overcome the stimulus, these criteria were (1) a change in both amplitude and frequency of the ventilatory pattern for more than two breaths, (2) an observed behavioral response (usually turning the head away from the stimulus), (3) a heart rate acceleration of $>10 \%$ above baseline, and (4) an increase in submental electromyographic activity. The $10 \mathrm{~s}$ of recording immediately preceding hypoxia-induced arousals provided baseline data to assess the degree of change in each physiologic variable.

Data analysis. HVR tests lasting at least $30 \mathrm{~s}$ were analyzed breath by breath, and mean values for $\mathrm{Spo}_{2}$ and $\mathrm{V}_{\mathrm{I}} / \mathrm{kg}$ were calculated in 15 -s epochs for the initial $30 \mathrm{~s}$ of each hypoxia test and expressed as the percentage of changes relative to baseline values. This initial 30 -s period was chosen for analysis to maximize the data in AS tests, which were invariably terminated by arousal. To assess the variability in $\dot{V}_{I} / \mathrm{kg}$ between infants, data from tests repeated in each infant were averaged for each sleep state, with arousing and nonarousing tests analyzed separately and standard deviations (SDs) of each group were compared using $F$ tests to investigate the effects of sleep state, the arousal response, and postnatal age. To assess the response variability observed within an infant, the difference between values of $\mathrm{V}_{\mathrm{I}} / \mathrm{kg}$ from repeated measurements $(n \geq 2)$ was calculated. The effects of sleep state and postnatal age were examined with a $t$ test and one-way analysis of variance, respectively.

\section{RESULTS}

A total of 254 hypoxic challenges was performed (115 in AS and 139 in QS). Of all tests, 54 in AS and 86 in QS provided suitable data for analyses of initial ventilatory responses. In response to hypoxia, infants consistently aroused from AS; however, in QS, infants both aroused and failed to arouse (17). In QS, the data have been grouped into arousal and nonarousal responses. Total sleep time recorded in the laboratory was not different from that recorded at home (when matched for time of day), except at 5-6 mo of age, when infants slept longer in the laboratory $(91 \pm 6$ versus $66 \pm 8$ $\min , p<0.05)(17,18)$.

\section{Ventilatory Responses to Hypoxia}

At each age, mild hypoxia induced a significant decrease in $\mathrm{SpO}_{2}$ in both sleep states, regardless of whether the infant aroused. In individual infants who aroused from sleep, $\mathrm{SpO}_{2}$ fell at a similar rate over the first $30 \mathrm{~s}$ of hypoxia in both AS and QS, as illustrated for the 2-5 wk study (Fig. 1A and $C$ ). The $\dot{V}_{\mathrm{I}} / \mathrm{kg}$ response, however was less consistent, with some infants exhibiting an increase, a decrease, or no change in $\dot{\mathrm{V}}_{\mathrm{I}} / \mathrm{kg}$ in response to hypoxia; furthermore, this variation appeared to be increased in AS compared with QS (Fig. 1B and $D$ ).

\section{Variability of $\dot{\mathbf{V}}_{\mathrm{I}} / \mathrm{kg}$ Responses Between Infants}

Effects of sleep state. The variability of ventilation (SD of $\dot{\mathrm{V}}_{\mathrm{I}} / \mathrm{kg}$ ) during the first $15 \mathrm{~s}$ of hypoxia was significantly increased in AS compared with QS when infants aroused at all three ages studied $(p<0.05)$. Similarly, after $30 \mathrm{~s}$ of hypoxia, $\dot{\mathrm{V}}_{\mathrm{I}} / \mathrm{kg}$ variability also tended to be greater in $\mathrm{AS}$; however, this
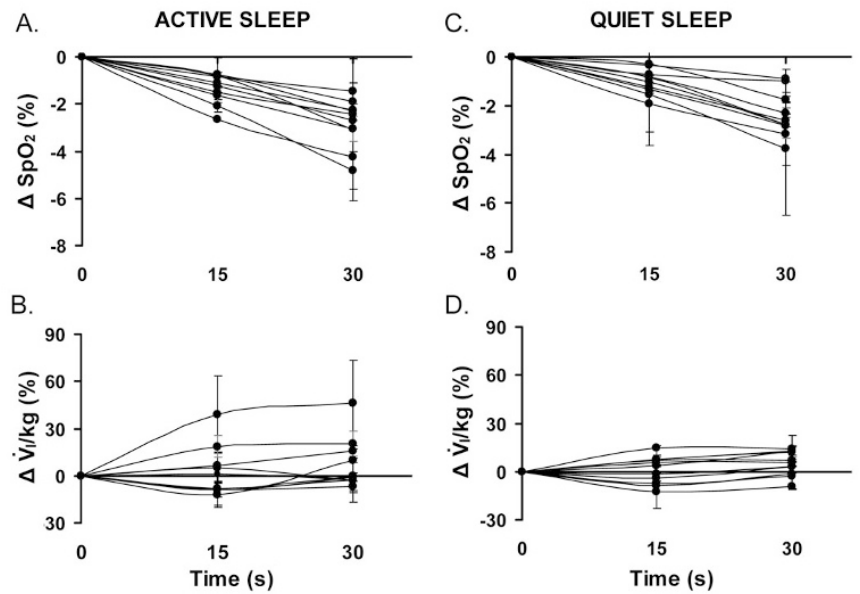

Figure 1. Individual infant responses to $15 \% \mathrm{O}_{2}$ at $2-5$ wk postnatal age during AS $(n=10)$ and QS $(n=11)$. The percentage of change in $\mathrm{Spo}_{2}$ after $15 \mathrm{~s}$ and $30 \mathrm{~s}$ of hypoxia in AS $(A)$ and QS $(B)$ sleep. The percentage of change in $\dot{\mathrm{V}}_{\mathrm{I}} / \mathrm{kg}$ after $15 \mathrm{~s}$ and $30 \mathrm{~s}$ of hypoxia in AS $(C)$ and QS $(D)$. Note the variability of $\dot{V}_{\mathrm{I}} / \mathrm{kg}$ between infants, particularly in AS. 
only reached statistical significance at $2-5$ wk postnatal age ( $p$ $<0.05)$ (Fig 2).

When arousal and nonarousal responses were compared after $15 \mathrm{~s}$ of hypoxia in QS $\dot{\mathrm{V}}_{\mathrm{I}} / \mathrm{kg}$, variability was greater when infants aroused at $2-3 \mathrm{mo}(p<0.05)$ and less at 5-6 mo $(p<$ 0.05 ), and at $2-5 \mathrm{wk}$, there was no difference. After $30 \mathrm{~s}$ of hypoxia, there was no difference between the variability of $\dot{\mathrm{V}}_{\mathrm{I}} / \mathrm{kg}$ responses associated with arousal or nonarousal responses at any age.

Effects of postnatal age. At both $2-5 \mathrm{wk}(p<0.05)$ and 2-3 mo $(p<0.05)$, the variability of $\dot{V}_{\mathrm{I}} / \mathrm{kg}$ after $15 \mathrm{~s}$ of hypoxia was significantly greater than at $5-6$ mo in AS. When arousal occurred during QS, the variation of $\dot{\mathrm{V}}_{\mathrm{I}} / \mathrm{kg}$ between infants also decreased with postnatal age, reaching significance at 5-6 mo $(p<0.05)$. In contrast, when hypoxia failed to induce arousal in QS, the ventilatory responses after $15 \mathrm{~s}$ were significantly less variable at 2-3 mo when compared with the other two ages studied $(p<0.05)$ (Fig. 3).

There were no effects of postnatal age on the variation in the HVR between infants after $30 \mathrm{~s}$ of hypoxia.

\section{Reproducibility of the Ventilatory Response in Individual Infants}

Effects of sleep state. For this analysis, only infants with two or more tests in each sleep state at a given age were included. As few infants failed to arouse from QS more than twice at a given age ( $2-5 \mathrm{wk}, n=0 ; 2-3 \mathrm{mo}, n=2 ; 5-6 \mathrm{mo}$, $n=3$ ), the QS arousal and nonarousal data have been combined. There were no significant differences in the variability of the HVR between data obtained in QS associated with arousal alone or with data from QS when arousal/ nonarousal data were combined (Fig. 4).

At 2-5 wk postnatal age, the variability between replicate $\dot{\mathrm{V}}_{\mathrm{I}} / \mathrm{kg}$ measurements was significantly greater in AS compared with QS at both $15 \mathrm{~s}(p<0.05)$ and $30 \mathrm{~s}(p<0.01)$. Although this trend was also observed at 2-3 mo and 5-6 mo, the differences did not reach statistical significance.

Effects of postnatal age. $\dot{\mathrm{V}}_{\mathrm{I}} / \mathrm{kg}$ differences between replicate tests did not differ significantly with postnatal age in either sleep state.

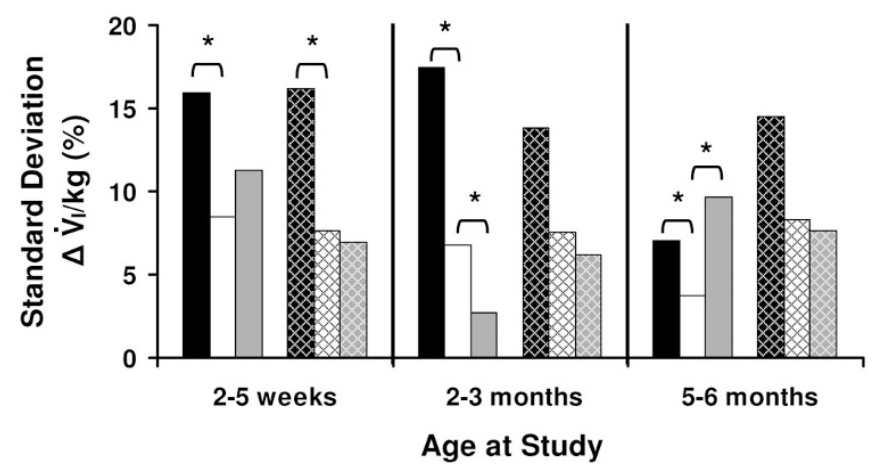

Figure 2. Effects of sleep state and arousal on the variability between infants of the percentage of change in $\dot{\mathrm{V}}_{\mathrm{I}} / \mathrm{kg}$ following $15 \mathrm{~s}$ (solid columns) and $30 \mathrm{~s}$ (cross-hatched columns) of hypoxia during AS (black columns), and QS when infants aroused (open columns) or failed to arouse (shaded columns). ${ }^{*} p<$ 0.05 .

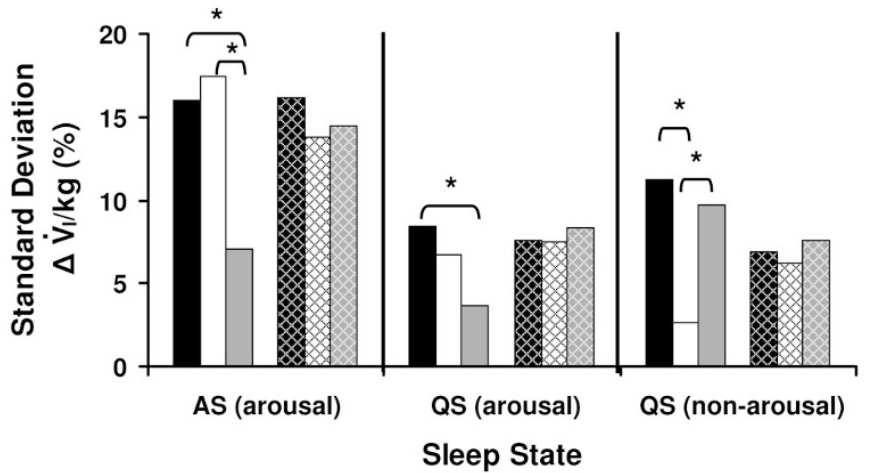

Figure 3. Effects of postnatal age on the variability between infants of the percentage of change in $\dot{\mathrm{V}}_{\mathrm{I}} / \mathrm{kg}$ following $15 \mathrm{~s}$ (solid columns) and $30 \mathrm{~s}$ (cross-hatched columns) of hypoxia at 2-5 wk (solid columns), 2-3 mo (open columns) and 5-6 mo (shaded columns) of postnatal age. ${ }^{*} p<0.05$.

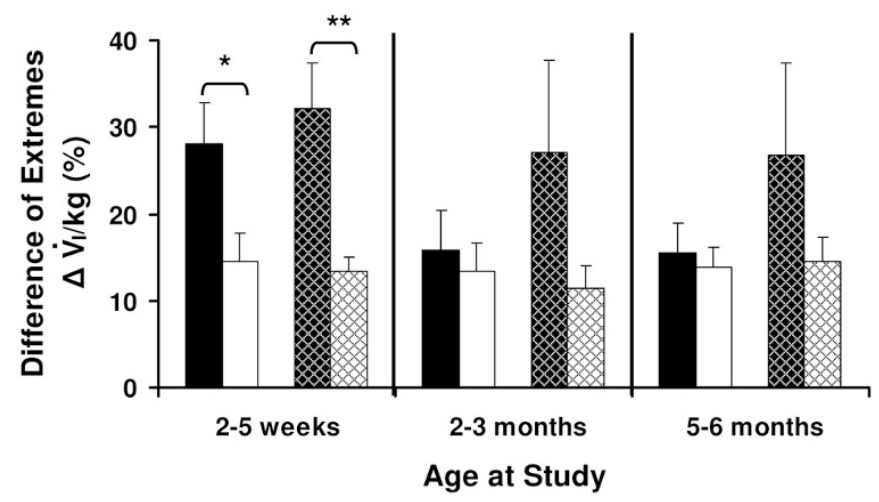

Figure 4. Effects of sleep state on within-infant variability of the percentage of change in $\dot{\mathrm{V}}_{\mathrm{I}} / \mathrm{kg}$ following repeated hypoxic test after $15 \mathrm{~s}$ (solid columns) and $30 \mathrm{~s}$ (cross-hatched columns) of hypoxia in AS (solid columns) and QS (open columns). $* p<0.05, * * p<0.01$. Note that arousal and nonarousal data in QS were combined for this analysis.

\section{Habituation of Ventilatory and Arousal Responses}

There was no evidence of habituation to repeated hypoxic tests in either sleep state. An example of test-to-test variation for one infant at 2-5 wk is presented in Figure 5; arousal and ventilatory responses of each infant were not progressive and
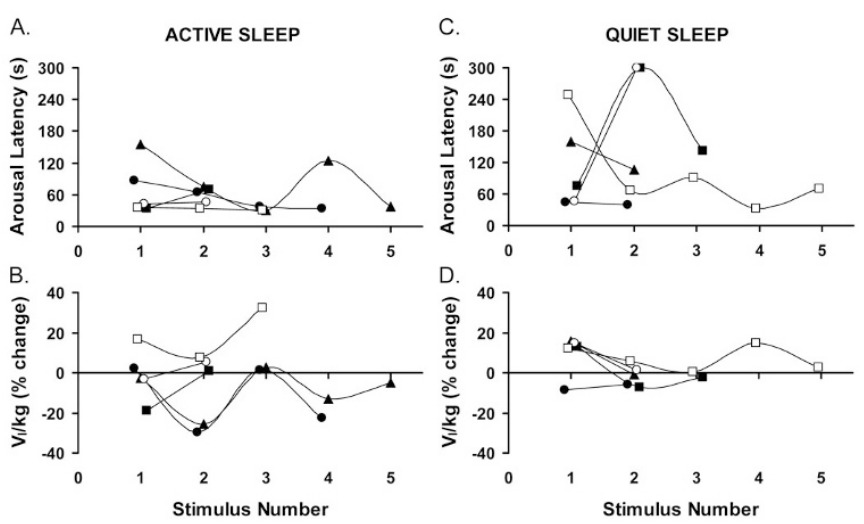

Figure 5. Effects of repeated hypoxic tests on arousal and ventilatory responses during AS and QS in infants $(n=5)$ at $2-5$ wk postnatal age. Arousal latency in AS $(A)$ and QS $(B)$. The percentage of change in $\dot{\mathrm{V}}_{\mathrm{I}} / \mathrm{kg}$ in AS $(C)$ and QS $(D)$. Note that there is no consistent change in responsiveness as measured by either arousal latency or percentage of change in $\dot{\mathrm{V}}_{\mathrm{I}} / \mathrm{kg}$. 
appeared to be random; that is, neither arousal latency nor $\dot{\mathrm{V}}_{\mathrm{I}} / \mathrm{kg}$ increased or decreased progressively with the number of repeated tests.

\section{DISCUSSION}

This is the first study to investigate the variability of the initial phase of the HVR between and within term infants over the first 6 mo of life. The testing of infants in both AS and QS and the separate analysis of responses in QS that either induced arousal or in which arousal failed to occur are also novel aspects of this study. Our study has demonstrated that the initial phase of the HVR varies between term infants during both AS and QS, with responses being markedly more variable during AS, and becoming more consistent with increasing postnatal age. Ventilatory and arousal responses also vary in an individual infant, but do not show any habituation to repeated tests. We suggest that by performing only one test or by failing to account for arousal responses, previous studies may not have detected the natural variation of the infant HVR.

Our study reveals considerable variation both between and within infants in both hypoxic ventilatory and arousal responses at all three ages studied. In the only other study to perform repeated hypoxic tests in term infants, Cohen et al. (7) also demonstrated a significant variability in the reproducibility of tests. They reported that less than half of the duplicate tests in QS produced similar ventilatory responses and suggested that QS was not a homogeneous state. Our study has expanded on these findings by studying infants in both AS and QS and also longitudinally over the first 6 mo of life. Our data are supported by those for adults in which repeated hypoxic tests in both NREM and REM sleep have also demonstrated significant variability in both ventilatory and arousal responses (16).

Our finding that HVRs were more variable in AS compared with QS may be another reflection of the physiologic variability of this sleep state. In infants, cardiorespiratory disturbances occur predominantly in AS. Therefore, given that AS is the dominant sleep state in infancy, infants may be at greater risk of cardiorespiratory instability in this state (25).

Previous studies by other groups of the HVR in term infants have been conducted only in QS. Recently we showed that, in infants challenged by mild hypoxia, arousal is always elicited in AS, whereas in QS, the same infant both aroused and failed to arouse to tests in QS (17); we also found that the arousal latency is also longer in QS. These findings are consistent with other studies using different respiratory stimuli $(26,27)$ and somatosensory stimuli $(21,22,28,29)$. Our finding that infants frequently fail to arouse in QS has previously been reported by us (30) and others (31-38), and the novel finding that infants always aroused in AS highlights the importance of arousal in this state. Arousal from sleep is accompanied by an increase in heart rate, arterial pressure, and ventilation (39), and, importantly, a behavioral response is evoked, allowing body movements aimed at avoiding the life-threatening challenge (40). Arousal from sleep has been described as a vital protective mechanism against cardiorespiratory failure (40), and de- pressed arousal responses have been implicated in sudden infant death sysndrome (SIDS) (41).

Our study did not reveal any habituation to repeated tests of either ventilatory or arousal responses; this is consistent with previous findings from our group using nasal air-jet stimulation (28). In contrast, there is significant habituation in infants to repeated tactile stimuli, and this occurred more rapidly in REM sleep (42). Habituation to a nonthreatening stimulus such as tactile stimulation of the foot, as used in this study, may be advantageous to preserve sleep continuity; however, habituation to a life-threatening stimulus such as hypoxia could have serious consequences for the individual and would certainly be maladaptive. It has been suggested by some authors that SIDS may result from a depression of ventilatory or arousal responses to repeated episodes of hypoxia (43); however, our study has shown that infants do not appear to habituate to small numbers (fewer than five) of hypoxic challenges.

In summary, we have shown that repeated hypoxic tests in both AS and QS do not result in habituation and provide a more accurate measure of individual responses to hypoxia that are variable.

Acknowledgments. The authors thank the parents and infants who participated in this study and the staff of the maternity wards and Jessie McPherson Private Hospital, Monash Medical Centre.

\section{REFERENCES}

1. Sauerland EK, Harper RM 1976 The human tongue during sleep: electromyographic activity of the genioglossus muscle. Exp Neurol 51:160-170

2. Hudgel DW, Martin RJ, Johnson B, Hill P 1984 Mechanics of the respiratory system and breathing pattern during sleep in normal humans. J Appl Physiol 56:133-137

3. Hudgel DW, Devadatta P 1984 Decrease in functional residual capacity during sleep in normal humans. J Appl Physiol 57:1319-1322

4. Rosen CL 2000 Maturation of breathing during sleep. Infants through adolescents. In: Loughlin GM, Carroll JL, Marcus CL (eds) Sleep and Breathing in Children. A Developmental Approach. Marcel Dekker, New York, pp 181-205

5. Read DJ, Henderson-Smart DJ 1984 Regulation of breathing in the newborn during different behavioral states. Annu Rev Physiol 46:675-685

6. Easton PA, Slykerman LJ, Anthonisen NR 1986 Ventilatory response to sustained hypoxia in normal adults. J Appl Physiol 61:906-911

7. Cohen G, Malcolm G, Henderson-Smart D 1997 Ventilatory response of the newborn infant to mild hypoxia. Pediatr Pulmonol 24:163-172

8. Cross KW, Warner P 1951 The effect of inhalation of high and low oxygen concentrations on the respiration of the newborn infant. J Physiol 114:283-295

9. Brady JP, Ceruti E 1966 Chemoreceptor reflexes in the newborn infant: effects of varying degrees of hypoxia on heart rate and ventilation in a warm environment. J Physiol 184:631-645

10. Martin RJ, DiFiore JM, Jana L, Davis RL, Miller MJ, Coles SK, Dick TE 1998 Persistence of the biphasic ventilatory response to hypoxia in preterm infants. J Pediatr 132:960-964

11. Cross KW, Oppe TE 1952 The effect of inhalation of high and low concentrations of oxygen on the respiration of the premature infant. J Physiol 117:38-55

12. Rigatto H, Brady JP, de la Torre Verduzco R 1975 Chemoreceptor reflexes in preterm infants: I. The effect of gestational and postnatal age on the ventilatory response to inhalation of $100 \%$ and $15 \%$ oxygen. Pediatrics 55:604-613

13. Sankaran K, Wiebe H, Seshia MM, Boychuk RB, Cates D, Rigatto H 1979 Immediate and late ventilatory response to high and low $\mathrm{O}_{2}$ in preterm infants and adult subjects. Pediatr Res 13:875-878

14. Alvaro R, Alvarez J, Kwiatkowski K, Cates D, Rigatto H 1992 Small preterm infants (less than or equal to $1500 \mathrm{~g}$ ) have only a sustained decrease in ventilation in response to hypoxia. Pediatr Res 32:403-406

15. Rigatto H, Kalapesi Z, Leahy FN, Durand M, MacCallum M, Cates D 1982 Ventilatory response to $100 \%$ and $15 \% \mathrm{O}_{2}$ during wakefulness and sleep in preterm infants. Early Hum Dev 7:1-10

16. Berthon-Jones M, Sullivan CE 1982 Ventilatory and arousal responses to hypoxia in sleeping humans. Am Rev Respir Dis 125:632-639 
17. Parslow PM, Cranage SM, Adamson TM, Harding R, Horne RS 2004 Arousal and ventilatory responses to hypoxia in sleeping infants: effects of maternal smoking. Respir Physiol Neurobiol 140:77-87

18. Parslow PM, Harding R, Cranage SM, Adamson TM, Horne RS 2003 Ventilatory responses preceding hypoxia-induced arousal in infants: effects of sleep-state. Respir Physiol Neurobiol 136:235-247

19. Anders T, Emde R, Parmelee A 1971 A Manual of Standardized Terminology, Techniques and Criteria for Scoring of States of Sleep and Wakefulness in Newborn Infants. UCLA Brain Information Service, Los Angeles

20. Horne RS, Sly DJ, Cranage SM, Chau B, Adamson TM 2000 Effects of prematurity on arousal from sleep in the newborn infant. Pediatr Res 47:468-474

21. Horne RS, Ferens D, Watts AM, Vitkovic J, Lacey B, Andrew S, Cranage SM, Chau B, Adamson TM 2001 The prone sleeping position impairs arousability in term infants. J Pediatr 138:811-816

22. Horne RS, Ferens D, Watts AM, Vitkovic J, Lacey B, Andrew S, Cranage SM, Chau B, Greaves R, Adamson TM 2002 Effects of maternal tobacco smoking, sleeping position and sleep state on arousal in healthy term infants. Arch Dis Child Fetal Neonatal Ed 87:F100-F105

23. The International Paediatric Work Group on Arousals 2005 The scoring of arousals in healthy term infants (between the ages of 1 and 6 months). J Sleep Res 14:37-41

24. Deleted in proof

25. Gaultier C 1995 Cardiorespiratory adaptation during sleep in infants and children. Pediatr Pulmonol 19:105-117

26. Galland BC, Bolton DP, Taylor BJ, Sayers RM, Williams SM 2000 Ventilatory sensitivity to mild asphyxia: prone versus supine sleep position. Arch Dis Child 83:423-428

27. Campbell AJ, Bolton DP, Taylor BJ, Sayers RM 1998 Responses to an increasing asphyxia in infants: effects of age and sleep state. Respir Physiol 112:51-58

28. Read PA, Horne RS, Cranage SM, Walker AM, Walker DW, Adamson TM 1998 Dynamic changes in arousal threshold during sleep in the human infant. Pediatr Res 43:697-703

29. Trinder J, Newman NM, Le Grande M, Whitworth F, Kay A, Pirkis J, Jordan K 1990 Behavioural and EEG responses to auditory stimuli during sleep in newborn infants and in infants aged 3 months. Biol Psychol 31:213-227
30. Parslow PM, Harding R, Cranage SM, Adamson TM, Horne RS 2003 Arousa responses to somatosensory and mild hypoxic stimuli are depressed during quiet sleep in healthy term infants. Sleep 26:739-744

31. Lewis KW, Bosque EM 1995 Deficient hypoxia awakening response in infants of smoking mothers: possible relationship to sudden infant death syndrome. J Pediatr 127:691-699

32. Dunne KP, Fox GP, O'Regan M, Matthews TG 1992 Arousal responses in babies a risk of sudden infant death syndrome at different postnatal ages. Ir Med J 85:19-22

33. Hunt CE 1981 Abnormal hypercarbic and hypoxic sleep arousal responses in near-miss SIDS infants. Pediatr Res 15:1462-1464

34. McCulloch K, Brouillette RT, Guzzetta AJ, Hunt CE 1982 Arousal responses in near-miss sudden infant death syndrome and in normal infants. J Pediatr 101:911917

35. Brady JP, McCann EM 1985 Control of ventilation in subsequent siblings of victims of sudden infant death syndrome. J Pediatr 106:212-217

36. van der Hal AL, Rodriguez AM, Sargent CW, Platzker AC, Keens TG 1985 Hypoxic and hypercapneic arousal responses and prediction of subsequent apnea in apnea of infancy. Pediatrics 75:848-854

37. Milerad J, Hertzberg T, Wennergren G, Lagercrantz H 1989 Respiratory and arousal responses to hypoxia in apnoeic infants reinvestigated. Eur J Pediatr 148:565-570

38. Ward SL, Bautista DB, Keens TG 1992 Hypoxic arousal responses in normal infants. Pediatrics 89:860-864

39. Horner RL 1996 Autonomic consequences of arousal from sleep: mechanisms and implications. Sleep 19:S193-S195

40. Phillipson EA, Sullivan CE 1978 Arousal: the forgotten response to respiratory stimuli. Am Rev Respir Dis 118:807-809

41. Harper RM, Bandler R 1998 Finding the failure mechanism in sudden infant death syndrome. Nat Med 4:157-158

42. McNamara F, Wulbrand H, Thach BT 1999 Habituation of the infant arousal response. Sleep 22:320-326

43. Kahn A, Groswasser J, Rebuffat E, Sottiaux M, Blum D, Foerster M, Franco P, Bochner A, Alexander M, Bachy A, Richard P, Verghote M, Le Polain D, Wayenberg JL 1992 Sleep and cardiorespiratory characteristics of infant victims of sudden death: a prospective case-control study. Sleep 15:287-292 